\title{
Germinação de sementes de Platypodium elegans Vog. submetidas a diferentes tratamentos pré-germinativos e substratos
}

\author{
Mauro V. Pacheco ${ }^{1}$, Valderez P. Matos ${ }^{2}$, Mozart D. Barbosa ${ }^{1}$, Rinaldo L. C. Ferreira ${ }^{3}$ \& Marco A. A. Passos ${ }^{3}$
}

\section{RESUMO}

Visando o efeito de tratamentos pré-germinativos (testemunha; imersão em ácido clorídrico por 3 min; cortes longitudinais sem e com embebição em água) e substratos (areia e pó de coco) na germinação de sementes de Platypodium elegans Vog avaliou-se, no presente estudo, a porcentagem total, a primeira contagem e a velocidade de germinação das sementes, o comprimento e a massa seca das plântulas. Não houve diferença significativa para a porcentagem de germinação $(\bar{x}=51 \%)$, mas os cortes longitudinais proporcionaram maior velocidade de germinação $(\bar{x}=0,95)$ e maior porcentagem na primeira contagem $(\bar{x}=42 \%)$. O pó de coco e os cortes longitudinais promoveram maiores comprimento $(\bar{x}=13,5 \mathrm{~cm})$ e acumulação de massa seca $(\bar{x}=50,0 \mathrm{mg})$ das plântulas.

Palavras-chave: semente florestal, qualidade fisiológica, vigor

\section{Germination of Platypodium elegans Vog. seeds submitted to different pre-germinative treatments and substrates}

\begin{abstract}
The aim of this work was to evaluate the influence of germinative pretreatments (control; chloridric acid, for 3 min; longitudinal cuts without and with water soaking) and substrates (sand and coconut fiber) in the germination of Platypodium elegans Vog. seeds. The analyzed characteristics were: percentage of germination, first germination count, germination speed index, length and dry mass gain to seedlings. There was no significant difference for the germination percentage $(\bar{x}=51 \%)$, but the longitudinal cuts promoted higher indices of germination speed $(\bar{x}=0.95)$ and first germination count $(\bar{x}=42 \%)$. The coconut fiber and the longitudinal cuts induced greater length $(\bar{x}=13.5 \mathrm{~cm})$ and dry mass gain $(\bar{x}=50.0 \mathrm{mg})$ in the seedlings.
\end{abstract}

Key words: forest seed, physiological quality, vigor 


\section{INTRODUÇÃO}

Platypodium elegans Vog - Fabaceae (jacarandá-branco) é uma espécie de ocorrência natural no Cerrado e em zonas de transição Cerrado-Floresta Estacional; encontrada em terrenos bem drenados (Lorenzi, 1998), sua madeira é empregada na carpintaria e marcenaria; além disso, esta espécie apresenta potencial ornamental e, para a recomposição de áreas degradadas, o plantio em grandes áreas verdes e em sistemas agroflorestais (Schorr et al., 2004).

O fruto de $P$. elegans é do tipo sâmara, apresenta um núcleo seminífero envolto por pericarpo bastante rígido e contornado por alas coriáceas vascularizadas (Barroso et al., 1999); é praticamente impossível separar a semente do fruto (Lorenzi, 1998).

Muitas espécies florestais desenvolveram, ao longo do tempo, estratégias naturais de sobrevivência. As sementes podem permanecer no solo durante longos períodos e apresentar germinação baixa e irregular, mesmo estando viáveis e expostas às condições ambientais favoráveis, como forma de garantir que a futura plântula conseguirá se estabelecer na comunidade (Murdoch \& Ellis, 2000; Carvalho \& Nakagawa, 2000). Alguns autores, como Crepaldi et al. (1998), Araújo Neto \& Aguiar (2000), Bruno et al. (2001), Pacheco (2002), Franco \& Ferreira (2002), Matos et al. (2003, 2004) e Santos et al. (2004), têm dado ênfase a trabalhos sobre tratamentos pré-germinativos a fim de otimizar a porcentagem, a velocidade e a uniformidade da germinação de sementes de espécies nativas.

O substrato constitui fator significativo que afeta o comportamento germinativo das sementes e o posterior desenvolvimento das plântulas. Na escolha do substrato deve-se levar em consideração o tamanho da semente, sua exigência em relação à luz, facilidade para realização das contagens e avaliação das plântulas (Figliolia et al., 1993). O substrato ideal também deve apresentar boa capacidade de retenção de água e porosidade. A água disponibilizada adequadamente evita a formação de uma película sobre a semente e permite a entrada de oxigênio para iniciar o processo de respiração (Popinigis, 1985).

Dentre os substratos mais utilizados e prescritos em Brasil (1992) estão o papel (toalha, filtro e mata-borrão), a areia e o solo; entretanto, podem ser encontrados no mercado substratos alternativos que já estão sendo utilizados em testes e pesquisas na área florestal, como a fibra de sisal (Lacerda et al., 2003) e o pó-de-coco (Pacheco et al., 2006).

A impermeabilidade do tegumento à água constitui-se em uma das principais causas de dormência em sementes da família Fabaceae; desta forma, os tratamentos pré-germinativos são de extrema importância quando se deseja acelerar e uniformizar a germinação; dentre esses se destacam as escarificações mecânica e ácida e o tratamento com água quente (Popinigis, 1985).

Considerando-se que o núcleo seminífero de $P$. elegans se encontra envolto por pericarpo bastante rígido, objetivouse, com o presente trabalho, verificar a germinação das sementes e o vigor das plântulas de jacarandá-branco, submetidas a diferentes tratamentos pré-germinativos e semeadas em dois substratos.

\section{MATERIAL E MÉTODOS}

Os frutos de $P$. elegans foram coletados diretamente de árvores localizadas na Área de Preservação da Companhia de Saneamento de Minas Gerais - COPASA S.A. (1646’ 20” S e 43 39' 56” W), município de Juramento, norte do estado de Minas Gerais, em julho de 2003. O experimento foi conduzido no Laboratório de Sementes Florestais do Departamento de Ciência Florestal da Universidade Federal Rural de Pernambuco.

Neste trabalho, as sâmaras foram referidas como sementes para facilitar a compreensão do texto; após a homogeneização, as sementes foram submetidas aos seguintes tratamentos pré-germinativos: imersão em ácido clorídrico concentrado por três minutos; cortes longitudinais no pericarpo sem embebição em água e cortes longitudinais no pericarpo com embebição em água, durante 24 h. O controle (sâmaras intactas) correspondeu aos frutos que não receberam qualquer tratamento pré-germinativo; após a escarificação ácida as sementes foram lavadas em água corrente para eliminar os resíduos do ácido; em seguida, elas foram desinfestadas em solução de hipoclorito de sódio a 5\%, durante cinco minutos, e lavadas com água destilada.

Conduziu-se o teste de germinação em câmara de germinação na temperatura constante de $25^{\circ} \mathrm{C}$ e fotoperíodo de 8 h, utilizando-se lâmpadas fluorescentes do tipo luz do dia (4 x $20 \mathrm{~W}$ ); depois, as sementes foram postas para germinar nos substratos entre areia e pó de coco, em caixas plásticas transparentes de $11 \times 11 \times 3 \mathrm{~cm}$, com tampa.

Adotou-se, como critério de germinação, a emissão do epicótilo das plântulas normais; avaliaram-se-lhes os seguintes parâmetros: porcentagem total de germinação (\%) - correspondente à porcentagem de sementes germinadas até o $30^{\circ}$ dia após a instalação do experimento; primeira contagem da germinação (\%) - referente à porcentagem acumulada de sementes germinadas até o $16^{\circ}$ dia do início do teste; índice de velocidade de germinação - indicado de acordo com a fórmula apresentada por Maguire (1962); comprimento da plântula - foi medido, no final do teste de germinação, o epicótilo e a raiz primária das plântulas de cada repetição com o auxílio de uma régua graduada em milímetro; massa seca das plântulas - as plântulas foram submetidas a secagem em estufa, regulada a $65^{\circ} \mathrm{C}$, durante 24 h, cujos resultados são expressos em massa seca (mg) por plântula.

Os tratamentos foram distribuídos segundo o delineamento experimental inteiramente casualizado e a análise de variância foi efetuada em arranjo fatorial 4 x 2 (quatro tratamentos pré-germinativos e dois substratos), com quatro repetições de 20 sementes cada uma. Utilizou-se, para a análise dos dados, o software estatístico The SAS System for Windows (Statistical Analysis System), versão 8.02. SAS Institute Inc., 1999-2001, Cary, NC, USA; as médias foram comparadas pelos testes $\mathrm{F}$ e de Tukey, a 5\% de probabilidade. Não houve necessidade de transformação dos dados, conforme os testes de normalidade e homogeneidade de variâncias previamente realizados. 


\section{RESULTADOS E DISCUSSÃO}

As médias da porcentagem total de germinação das sementes de $P$. elegans encontram-se na Figura 1, na qual não se observa efeito significativo, seja entre os tratamentos prégerminativos ou entre os substratos utilizados.

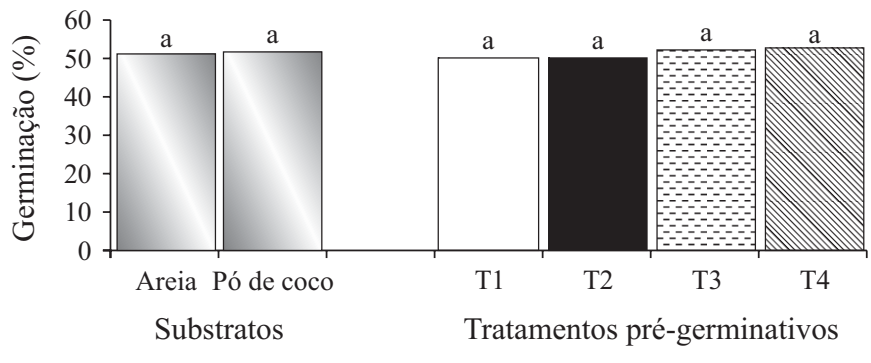

Figura 1. Porcentagem total de germinação das sementes de Platypodium elegans Vog. submetidas a dois substratos (areia e pó de coco) e diferentes tratamentos pré-germinativos (T1 - Testemunha; T2 - Ácido clorídrico por 3 min; T3 - Corte longitudinal sem embebição; T4 - Corte longitudinal com embebição por $24 \mathrm{~h}$ ). Médias seguidas da mesma letra não diferem entre si pelo teste de Tukey ( $P>0,05)$. $C V=16,6 \%$

A remoção de parte do pericarpo através de cortes longitudinais, além de aumentar a permeabilidade à água, pode induzir a um aumento da sensibilidade à luz, à temperatura, à permeabilidade aos gases, à remoção de inibidores e pro-

A.

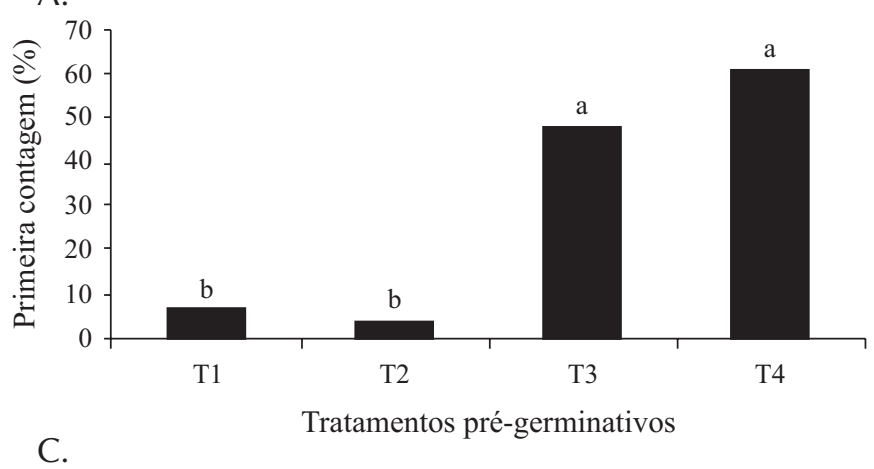

C

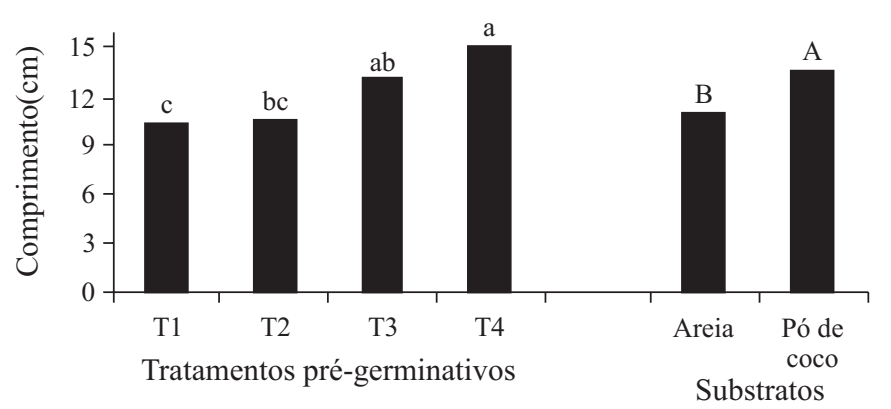

motores e à possibilidade de injúria aos tecidos exercendo, assim, significante influência no metabolismo das sementes (Mayer \& Poljakoff-Mayber, 1989).

Nas Figuras 2A e 2B se encontram as comparações entre as médias da primeira contagem e do índice de velocidade de germinação das sementes submetidas a diferentes substratos e tratamentos pré-germinativos; apenas os tratamentos pré-germinativos afetaram significativamente essas características avaliadas, sendo que os maiores valores da primeira contagem e do índice de velocidade da germinação ocorreram nos tratamentos com cortes longitudinais no núcleo seminífero, independentemente da embebição em água, comprovando que o tegumento da semente não apresenta impermeabilidade à água; em contrapartida, os menores resultados foram proporcionados pelo tratamento com ácido clorídrico durante três minutos e não diferiram estatisticamente do controle. Possivelmente se deva a redução na velocidade da germinação ao tempo inadequado de imersão no ácido clorídrico (Figura 2B).

Efeitos significativos para os substratos e tratamentos prégerminativos foram observados para o comprimento das plântulas, embora a interação entre esses fatores não tenha sido significativa (Figura 2C). Obtiveram-se os maiores valores nos tratamentos com cortes longitudinais no pericarpo com e sem embebição. Quando o substrato pó de coco foi utilizado observou-se maior comprimento das plântulas.
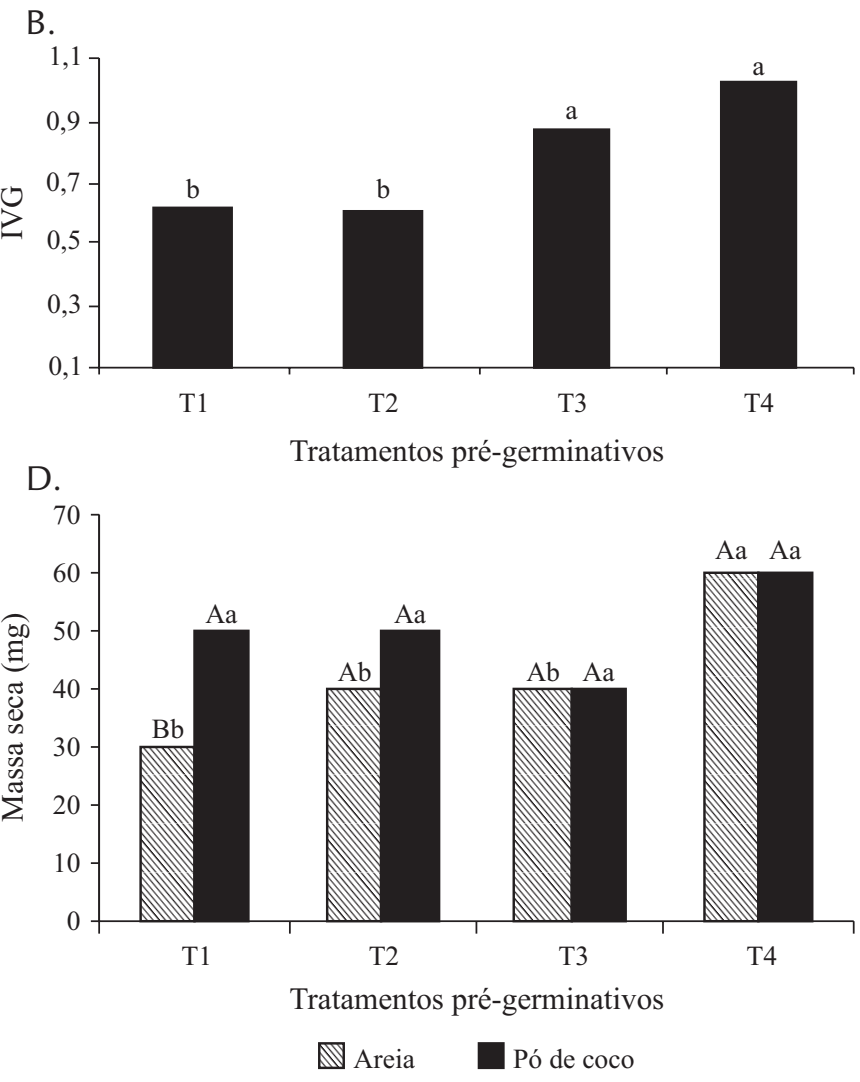

Figura 2. Testes de vigor em sementes de Platypodium elegans Vog. submetidas a diferentes tratamentos pré-germinativos (T1 - Testemunha; T2 - Ácido clorídrico por 3 min; T3 - Corte longitudinal sem embebição; T4 - Corte longitudinal com embebição por 24 h) e dois substratos (areia e pó de coco). A - Primeira contagem da germinação $(\%)(C V=34,0 \%) ; B-$ Índice de velocidade de germinação $(C V=18,6 \%) ; C-C o m p r i m e n t o ~(c m)$ de plântulas $(C V=16,5 \%) ; D$ - Massa seca $(\mathrm{mg})$ de plântulas $(C V=16,01 \%)$. Médias seguidas da mesma letra maiúscula (substratos) e minúscula (tratamentos prégerminativos), não diferem entre si pelos testes $\mathrm{F}$ e de Tukey, respectivamente $(P>0,05)$ 
A interação entre substratos e tratamentos pré-germinativos, referente à massa seca das plântulas, foi significativa (Figura 2D). Obtiveram-se, com pó de coco, valores médios de 40,0 a 60,0 mg, não tendo havido diferença significativa entre eles. Silveira et al. (2002) ao utilizarem o pó de coco para produção de mudas de tomateiro, também detectaram, além de bons resultados na germinação das sementes, incrementos no comprimento e na massa seca das plântulas.

Entre areia, a melhor combinação para massa seca das plântulas ocorreu quando se utilizou o tratamento corte longitudinal com embebição (60,0 mg), significativamente superior ao controle (30,0 mg) (Figura 2D), resultado este que pode ser explicado pelo fato de que o corte no pericarpo com prévia embebição proporcionou maior velocidade na germinação das sementes (Figura 2B) e, conseqüentemente, maior comprimento das plântulas (Figura 2C).

Alguns autores (Machado et al., 2002; Franco \& Ferreira, 2002; Nogueira et al., 2003) têm obtido bons resultados de germinação de sementes nativas ao adotarem a areia como substrato. Figliolia et al. (1993) afirmam que a areia é muito utilizada quando se comparam diferentes substratos mas apresenta, dentre outros inconvenientes, falta de uniformidade com relação à retenção e à distribuição de água.

Andrade et al. (1999) observaram que a areia exigiu freqüente reposição de água durante os testes de germinação de sementes de Euterpe edulis Mart. No presente trabalho, a necessidade de reumedecimento diário do substrato areia foi maior que no pó de coco. De acordo com Carrijo et al. (2002), as propriedades físicas do pó de coco conferem características satisfatórias à sua utilização como substrato: alta porosidade $(95,6 \%)$; ótima capacidade de retenção de água (538 $\mathrm{mL} \mathrm{L}^{-1}$ ) e capacidade de aeração (45,5\%); ainda segundo esses autores, as fibras do pó de coco são praticamente inertes e não possuem os nutrientes essenciais para o desenvolvimento das plântulas apresentando, também, outras vantagens, como baixo custo e facilidade de obtenção.

O beneficiamento da casca de coco verde, subproduto da indústria da água de coco, é extremamente importante, haja vista que seu acúmulo nos lixões e aterros sanitários acarreta sérios problemas ambientais, levando até oito anos para se decompor (Carrijo et al., 2002). Desta forma, o pó de coco é uma alternativa ecologicamente correta que permite a redução da disposição de resíduos sólidos, além de evitar a utilização de substratos (areia, vermiculita) que produzem impactos ambientais negativos (Rosa et al., 2001).

\section{CONCLUSÕES}

1. Os tratamentos pré-germinativos e os substratos utilizados não influenciaram a porcentagem de germinação de sementes de jacarandá-branco.

2. Os cortes longitudinais no pericarpo (sem e com embebição em água) e a utilização do substrato pó de coco, proporcionaram maior velocidade de germinação das sementes e obtenção de plântulas mais vigorosas.

\section{LITERATURA CITADA}

Andrade, A. C. S.; Loureiro, M. B.; Souza, A. D.; Ramos, F. N.; Cruz, A. P. M. Reavaliação do efeito do substrato e da temperatura na germinação de sementes de palmiteiro (Euterpe edulis Mart.). Revista Árvore, Viçosa, v.23, n.3, p.279-283, 1999.

Araújo Neto, J. C.; Aguiar, I. B. Germinative pretreatments to dormancy break in Guazuma ulmifolia Lam. seeds. Scientia Forestalis, Piracicaba, v.58, n.1, p.15-24, 2000.

Barroso, G. M.; Morim, M. P.; Peixoto, A. L.; Ichaso, C. L. F. Frutos e sementes: Morfologia aplicada à sistemática de dicotiledôneas. Viçosa: UFV, 1999. 443p.

Brasil. Ministério da Agricultura e Reforma Agrária. Regras para análise de sementes. Brasília: SNDA/DNDV/CLAV, 1992. 365p.

Bruno, R. L. A.; Alves, E. U.; Oliveira, A. P.; Paula, R. C. Tratamentos pré-germinativos para superar a dormência de sementes de Mimosa caesalpiniaefolia Benth. Revista Brasileira de Sementes, Brasília, v.23, n.2, p.136-143, 2001.

Carrijo, O. A.; Liz, R. S.; Makishima, N. Fibra da casca do coco verde como substrato agrícola. Horticultura Brasileira, Brasília, v.20, n.4, p.533-535, 2002.

Carvalho, N. M.; Nakagawa, J. Sementes: Ciência, tecnologia e produção. Jaboticabal: FUNEP, 2000. 588p.

Crepaldi, I. C.; Santana, J. R. F.; Lima, P. B. Quebra de dormência de sementes de pau-ferro (Caesalpinia ferrea Mart. Ex Tul.Leguminosae, Caesalpinioideae). Sitientibus, Feira de Santana, v.17, n.8, p.19-29, 1998.

Figliolia, M. B.; Oliveira, E. C.; Pinã-Rodrigues, F. C. M. Análise de sementes. In: Aguiar, I. B.; Pinã-Rodrigues, F. C. M.; Figliolia, M. B. Sementes florestais tropicais. Brasília: ABRATES, 1993. p.137-174p.

Franco, E. T. H.; Ferreira, A. G. Tratamentos pré-germinativos em sementes de Didymopanax morototoni (Aubl.) Dene. et planch. Ciência Florestal, Santa Maria, v.12, n.1, p.1-10, 2002.

Lacerda, M. R. B.; Barbosa, M. D.; Passos, M. A. A.; Rodrigues, J. J. V.; Gomes, R. V.; Matos, V. P.; Silva, T. C.; Barbosa, U. N. Germinação de sementes de sabiá (Mimosa caesalpiniaefolia, Benth) em diferentes substratos em condições de viveiro. In: Simpósio de Pesquisa e Pós-Graduação da UFRPE, 4, 2003, Recife. Resumos... Recife: UFRPE, 2003. CD Rom

Lorenzi, H. Árvores brasileiras: Manual de identificação e cultivo de plantas arbóreas nativas do Brasil. Nova Odessa: Plantarum, 1998. 368p.

Machado, C. F.; Oliveira, J. A.; Davide, A. C.; Guimarães, R. M. Metodologia para a condução do teste de germinação em sementes de ipê-amarelo (Tabebuia serratifolia (Vahl) Nicholson). Cerne, Lavras, v.8, n.2, p.18-27, 2002.

Maguire, J. D. Speed of germination-aid in selection and evaluation for seedlings emergence and vigor. Crop Science, Madison, v.2, n.1, p.176-177, 1962.

Matos, V. P.; Azerêdo, G. A.; Gonçalves, E. P.; Silva, A.; Rodrigues, L. F. Sementes de sapoti (Achras sapota L.): Dormência e emergência. Pesquisa Agropecuária Tropical, Goiânia, v.33, n.2, p.71-74, 2003.

Matos, V. P.; Santos, T. O.; Morais, T. G. O. Tratamentos pré-germinativos para superação de dormência em sementes de chichá (Sterculia foetida). Revista Árvore, Viçosa, v.28, n.1, p.171-177, 2004. 
Mayer, A. M.; Poljakoff-Mayber, A. The germination of seeds. Great Britain: Pergamon Press, 1989. 270p.

Murdoch, A. J.; Ellis, R. H. Dormancy, viability and longevity. In: Fenner, M. (Ed.) Seeds: the ecology of regeneration in plant communities. 2.ed. Wallingford: CABI Publishing, 2000. p.183-214.

Nogueira, R. J. M. C.; Albuquerque, M. B.; Silva Jr., J. F. Efeito do substrato na emergência, crescimento e comportamento estomático em plântulas de mangabeira. Revista Brasileira de Fruticultura, Jaboticabal, v.25, n.1, p.15-18, 2003.

Pacheco, M. V. Superação de dormência em sementes de Caryocar brasiliense Camb. Montes Claros: UNIMONTES, 2002. 31p. Monografia Graduação

Pacheco, M. V.; Matos, V. P.; Ferreira, R. L. C.; Feliciano, A. L. P.; Pinto, K. M. S. Efeito de temperaturas e substratos na germinação de sementes de Myracrodruon urundeuva Fr. All. (Anacardiaceae). Revista Árvore, Viçosa, v.30, n.3, p.359-367, 2006.
Popinigis, F. Fisiologia da semente. 5.ed. Brasília: AGIPLAN, 1985. 289p.

Rosa, M. F.; Abreu, F. A. P.; Furtado, A. A. L.; Brígido, A. K. L.; Norões, E. R. V. Processo agroindustrial: Obtenção de pó de casca de coco verde. Fortaleza: Embrapa Agroindústria Tropical, 2001. 6p. Comunicado Técnico, 61

Santos, T. O.; Morais, T. G. O.; Matos, V. P. Escarificação mecânica em sementes de dchichá (Sterculia foetida L.). Revista Árvore, Viçosa, v.28, n.1, p.1-6, 2004.

Schorr, M.; Sponholz, N.; Portilho, I. S. Desenvolvimento sustentável para o Vale do Ribeira. http://www.planetaorganico.com.br/ TrabSchorr.htm. 09 Ago. 2004.

Silveira, E. B.; Rodrigues, V. J. L. B.; Gomes, A. M. A.; Mariano, R. L. R.; Mesquita, J.C.P. Pó de coco como substrato para produção de mudas de tomateiro. Horticultura Brasileira, Brasília, v.20, n.2, p.211-216, 2002. 